\title{
Hidden in Plain Sight: The Psychological Benefits of Personal Quantification
}

Stephen Flora ${ }^{\star}$ and Kristopher Brown

Youngstown State University, 1 University Plaza, Youngstown, Ohio, United States

\begin{abstract}
Background: Behavior analysis relies on the measurement and quantification of behavior. Recent research has argued that measuring and quantifying behavior may have detrimental effects on the measured behaviors. To investigate this claim, the current study surveyed avid cyclists to assess their reported yearly biking habits, use of personal quantification devices, reported interest/enjoyment in biking, and use of exercise-related social media platforms.
\end{abstract}

Methods: Two groups of avid bikers were surveyed about biking and how personal quantification affected interest. Participants were asked a series of questions about their cycling habits in general, their use of a bike computer for personal quantification, questions about their enjoyment in biking activities, and use of exercise-related social media platforms7

Results: Nearly all (94\%) bikers reported using computerized personal quantification using bike computers, reported high levels of enjoyment, and reported they found quantification made bicycling more enjoyable and interesting.

Conclusion: This result refutes claims that personal quantification undermines intrinsic interest, enjoyment, or happiness. Personal quantification facilitates continued activity engagement and sharing quantified information with other interested individuals may make interesting activities even more interesting. Rather than "undermine intrinsic interest" or "turn play into work," personal quantification is supplemental to the total activity experience. The results obtained here indicate personal quantification can facilitate expert performance and the experience of flow.

\section{Introduction}

Applied behavior analysis (ABA) depends on and is in part defined by the measurement of behavior and its quantification. "Since the behavior of an individual is composed of physical events, its scientific study requires their precise measurement. As a result, the problem of reliable quantification arises immediately" [1]. Without measurement or quantification, behavior analysis could not exist. Even outside of $\mathrm{ABA}$, the use of measurement is common across many subdisciplines of psychology. In sum, the use of objective data on operationally defined variables is a hallmark of a science of behavior.

Despite the ubiquity of behavior measurement in behavior analysis and related psychological disciplines, the psychological impact of personal quantification had not been the source of much attention until recently. Based on the results of six experiments that received wide media attention [2], recent analyses on the subject have argued that personal quantification has harmful psychological effects. In the paper, The Hidden Cost of Personal Quantification, Jordan Etkin states that: "measurement... can simultaneously reduce how much people enjoy those [quantified] activities... undermine intrinsic motivation... can make enjoyable activities feel more like work... measurement can decrease continued engagement in the activity and subjective wellbeing. [3, p. 967, emphasis added]. Etkin also states that these effects can occur even with the absence of external incentives for doing so. The question then is this: When people measure their behavior, does that measurement of behavior "rob them of some of the benefits of engaging in those activities?" [3, p. 967].

If this analysis of the effects of quantification on benefits of activity engagement is correct, it could be argued that the very practice of $\mathrm{ABA}$ is practically and/or ethically questionable on the grounds it reduces enjoyment in those activities being measured. Fortunately, inspection of the methods and results of Etkin [3] suggest the claims of detrimental effects of measurement are unwarranted. First, Etkin's participants were either anonymous college students who had to be paid in order to participate or were paid online participants from Amazon's Mechanical Turk. Having to compensate participation with money begs the question as to how "intrinsically interesting" the tasks were in the first place. Second, other than wearing a pedometer for a single day, Etkin's activities (drawing pictures with markers or reading nondescript passages) were brief samples of behavior that lasted no more than 10 minutes. It seems it would be difficult to argue about effects on broad factors such as intrinsic interest, work, enjoyment, or much less "continued engagement in the activity" [3 p. 967] with such brief samples of behavior in time [4]. Third, in several of Etkin's experiments the standard deviation within each group was greater, in several cases more than twice as great, than any difference between groups. Despite any "statistical significance" this range of measures and large overlap of scores between conditions suggests that the effects of any experimental manipulation could have been less significant for a number of participants.

Etkin's criticism of the effects of measurement and how it is like other "extrinsic factors impact intrinsic processes" relies specifically on a widely held, but highly questionable contention that "external rewards can undermine intrinsic interest" [3, p.967]. The general argument is that while "reward" may temporarily increase the rate of behavior, it will "undermine intrinsic interest," "turn play into work," reduce enjoyment, and destroy creativity [3: see 5 for review and analysis]. Some researchers have conducted meta-analyses and found "Corresponding Author: Dr. Stephen Flora, Youngstown State University, 1 University Plaza, Youngstown, Ohio, United States; E-mail: srflora@ysu.edu

Citation: Flora S, Brown K (2021) Hidden in Plain Sight: The Psychological Benefits of Personal Quantification. Int J Psychol Behav Anal 7: 174. doi: https://doi. org/10.15344/2455-3867/2021/174

Copyright: (C) 2021 Flora et al. This is an open-access article distributed under the terms of the Creative Commons Attribution License, which permits unrestricted use, distribution, and reproduction in any medium, provided the original author and source are credited. 
support for the argument that reward can undermine intrinsic interest [6]. Conversely, others have conducted their own meta-analyses and research reviews and concluded that rewards can increase interest and enjoyment in the rewarded activity, increase productivity, and even may increase creativity [7]

In addition to meta analyses that indicate the potential benefit of reinforcement on task interest, careful experimental analysis of contrived reinforcement procedures and systematic replications have established that the application of contrived reinforcement can increase interest, enjoyment, work productivity and creativity. As a rule, reinforcers increase whatever aspect(s) of behavior that the reinforcers are contingent on. For example, studies with young children [8], grade school children and college students [9], adult employees [10], older adults in an assisted living facility [11] have established the benefits of reinforcement on creativity, interest, and performance.

The current exploratory study was conducted to investigate if the psychological impact of measurement, or "personal quantification" is detrimental. To avoid the use of random, possibly trivial, or very brief activities to assess interest, a different approach was taken. Rather than recruit college students, completely unknown individuals, or compensate participants, the current study surveyed a group of individuals who freely engaged in a preferred activity for decades: amateur bikers. Instead of using small samples of behaviors, these individuals revealed their interest and motivation by how they spent their lives, how they spent their leisure time, and how they spent their income. Rather than pay people to participate, the current study looked at what people paid for in time and money as a free operant assessment of interest and surveyed about cycling and how personal quantification via a bike computer affected their level of interest.

\section{Materials and Method}

\section{Participants}

Two groups of regular bikers ("bikers") were surveyed about their interest, amount and enjoyment of cycling, and their use of a bike computer. Cyclist group 1 consisted of 16 bikers at a bicycling training camp/vacation on the island of Mallorca (Majorca) Spain. Of the bikers surveyed in Mallorca; four were from England, two from Ireland, one from Canada, six from the United States, and three did not indicate a home country. Eleven bikers indicated being male, three females, and two did not indicate a sex. The average age reported was 50.25 years. Cyclist group 2 consisted of 18 members of a local triathlon club in north east Ohio. All 18 triathletes were from the United States. Eleven were male, six female and one did not indicate a sex. The average was 47.58 years. The research received approval from the researcher's university's Institutional Review Board.

\section{Setting}

Bikers were surveyed in Mallorca, Spain or Northeastern Ohio. Mallorca is location used by several professional bike racing teams for late winter/early spring training camps and is a favorite spot for avid bikers of all kinds including noncompetitive bikers, professional, and amateur racers. The bikers from Mallorca were given the survey on the final evening or morning after a week of biking. The triathletes from Northeast Ohio were asked at their season end club awards banquet.

\section{Procedure}

Bikers were told a study was being conducted that looked at the exercise habits of regular bikers and asked to complete a survey on their habits. The first page of the surveyed contained the researcher's university contact information along with a statement indicating that completion of the survey implied consent.

\section{Survey}

After consenting, each participant was presented with a survey. The first page of the survey collected demographic information including age, sex, country of residence, how long (in years and months) the participant has worked out, exercised, or engaged in athletic pursuits. Participants were then asked a series of questions about their cycling habits in general, questions about their use of a bike computer (personal quantification device), questions about their enjoyment in biking activities, and use of exercise-related social media platforms (Appendix A and Appendix B) supplementary files. .For the purpose of the current study, bike computers were defined as personal quantification devices that provide quantified information to the cyclist about the cyclist's biking behavior and related physiological variables. Modern bike computers can measure, display, and record metrics such as speed, distance, time, calories used on a ride, power, cadence, heart rate, elevation (climbing), temperature, routes being ridden, and more. Bike computers are typically mounted on the bike's handlebars and can be viewed by the cyclist with a downward glance during riding to access these metrics. Examples of exerciserelated social media include Strava ${ }^{\star}$ and Garmin Connect ${ }^{\star}$. Strava and Garmin Connect are social media fitness data sharing platforms. Strava's basic platform is free to anyone. Garmin Connect requires the use of a Garmin product but is otherwise free. Both platforms allow for the sharing of cycling data with others.

\section{Results and Discussion}

Bikers surveyed in Mallorca reported working out, exercising, or engaging in athletic pursuits for an average of 33.50 years. On average the bikers biked $3810 \mathrm{~km}$ per year. In the summer they biked an average of $145.2 \mathrm{~km}$ per week and went biking 3.88 times per week. Triathletes from Northeast Ohio reported working out, exercising, or engaging in athletic pursuits for an average of 27.08 years. On average, the triathletes biked $3738.5 \mathrm{~km}$ per year. In the summer they biked an average of $275.5 \mathrm{~km}$ per week and reported biking 3.20 times per week.

\section{Personal levels of enjoyment}

Mallorca bikers reported they found biking highly enjoyable (6.56 on a 7-point scale) and reported low levels or boredom (1.69). Mallorca bikers found cycling very interesting (5.93), and indicated it was not a waste of time (1.13). They reported cycling to be very fun (6.44) and that it made them very happy (6.38). Likewise, triathletes found biking highly enjoyable (6.61) and reported low levels of boredom (1.72). Triathletes found cycling very interesting (6.5), and also indicated it was not a waste of time (1.06). They also reported that they found cycling very fun (6.72) and it made them very happy (6.72; see Figure 1).

\section{Personal quantification}

Nearly all (94\%) of surveyed bikers reported using personal quantification methods. All 16 (100\%) of the Mallorca bikers reported they used a bike computer. They reported they measured an average of 5.69 biking variables and tracked an average of 3.46 measures over the course of a year. Bikers from Mallorca reported that use of a bike computer made biking more enjoyable (4.93) and made biking more 
Citation: Flora S, Brown K (2021) Hidden in Plain Sight: The Psychological Benefits of Personal Quantification. Int J Psychol Behav Anal 7: 174. doi: https://doi. $\operatorname{org} / 10.15344 / 2455-3867 / 2021 / 174$

Page 3 of 7

interesting (5.38). Similarly, 16 of 18 (89\%) of the triathletes used a bike computer, measured an average of 5.5 biking variables and tracked an average of 4.06 measures over the course of a year. Triathletes reported that use of a bike computer made biking more enjoyable (6.0) and made biking more interesting (6.06). In sum, the majority of bikers from both groups reported that personal quantification increased their interest and enjoyment (Figure 2 and Figure 3, respectively).

\section{Use of social media}

In total, 8 of $16(50 \%)$ of bikers and 10 of $18(56 \%)$ of triathletes reported the use Strava or Garmin connect. There was confusion between using a Garmin computer as one's bike computer and the use of Garmin Connect as a social media platform to use and compare one's biking data. Therefore, data is only provided for those who used Strava. In total, 6 of 16 bikers (38\%) and 4 of $18(22 \%)$ triathletes reported the use of Strava. Bikers who reported using Strava indicated it made biking more enjoyable (6.0) and more interesting (5.83). On the 7-point scale, the triathletes who reported using Strava gave more moderate rating for Strava making biking more enjoyable (4.75) and for making biking more interesting (4.5).

\section{Conclusion}

In sum, avid, enthusiastic bikers surveyed reported high engagement in cycling. In general, respondents reported they have been involved in athletic pursuits for decades, bike thousands of kilometers per year, bike over $150 \mathrm{~km}$ a week, and reported biking over 3 times per week in the summer. Bikers reported finding biking highly enjoyable, did not indicate they found it boring, reported high interest, did

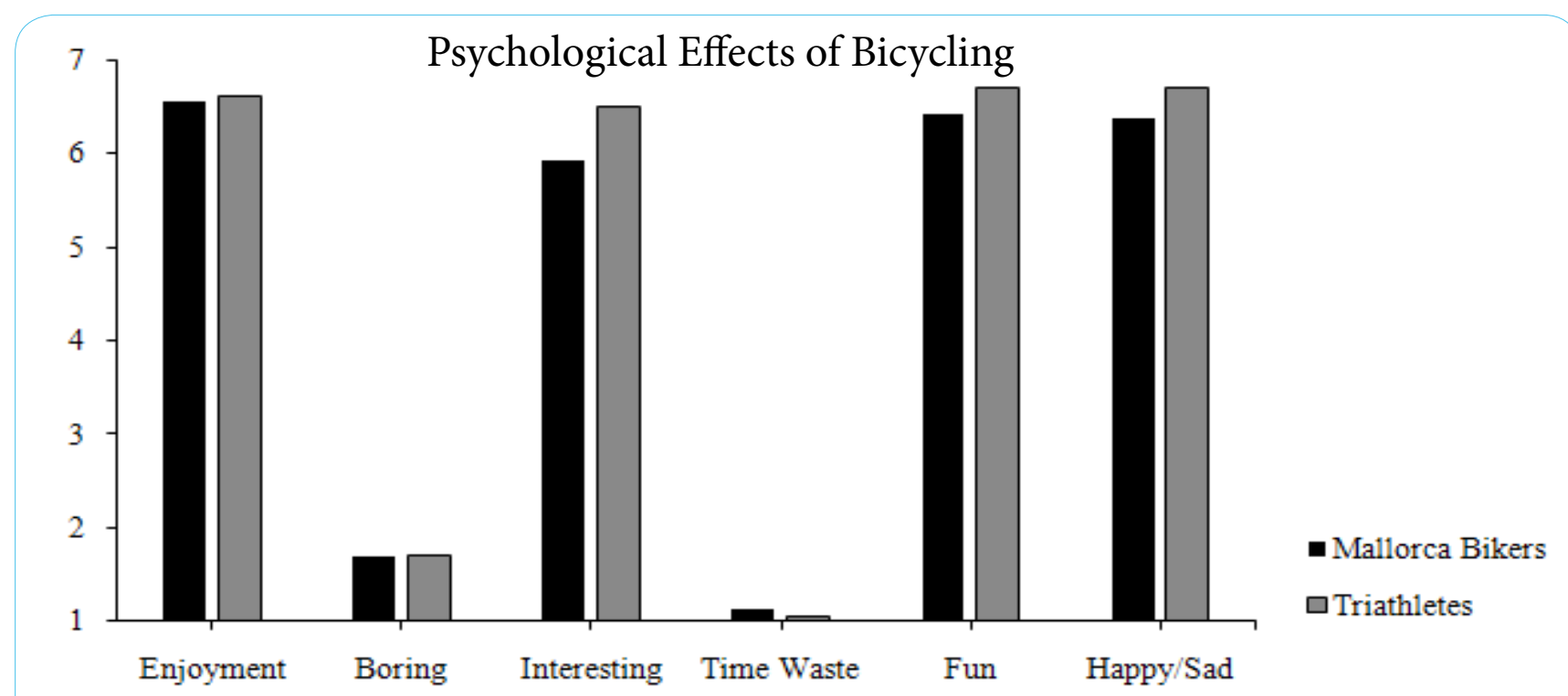

Figure 1: Reported psychological effects of bicycling by avid bikers. A 7 indicates most enjoyment, most boring, most interesting, most waste of time, most fun, and makes the biker most happy and least sad, a 4 is neutral. A 1 indicates least enjoyment, least boring, least interesting, least waste of time, least fun, and makes the biker least happy and most sad.

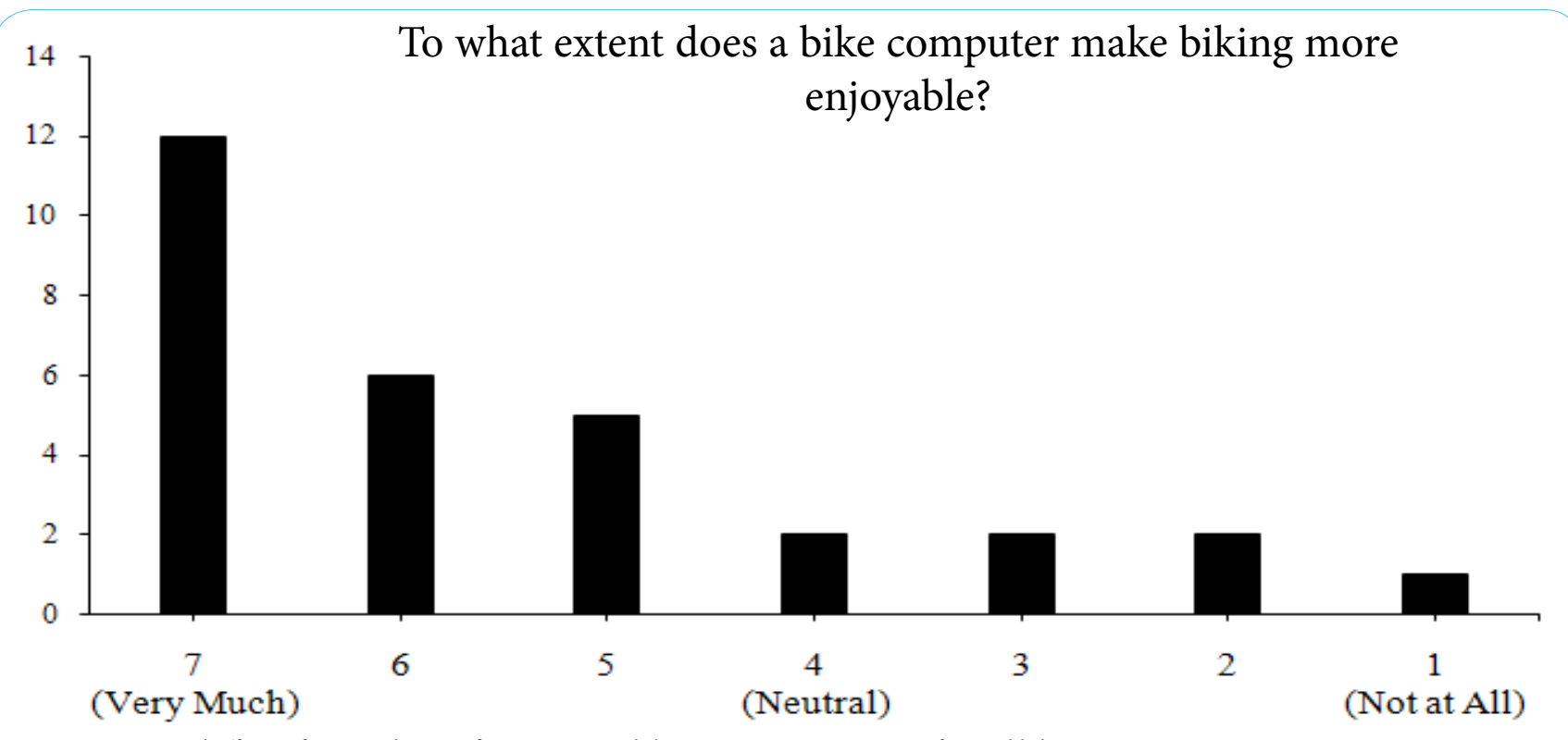

Figure 2: Reported effects of personal quantification using a bike computer on enjoyment for avid bikers. 


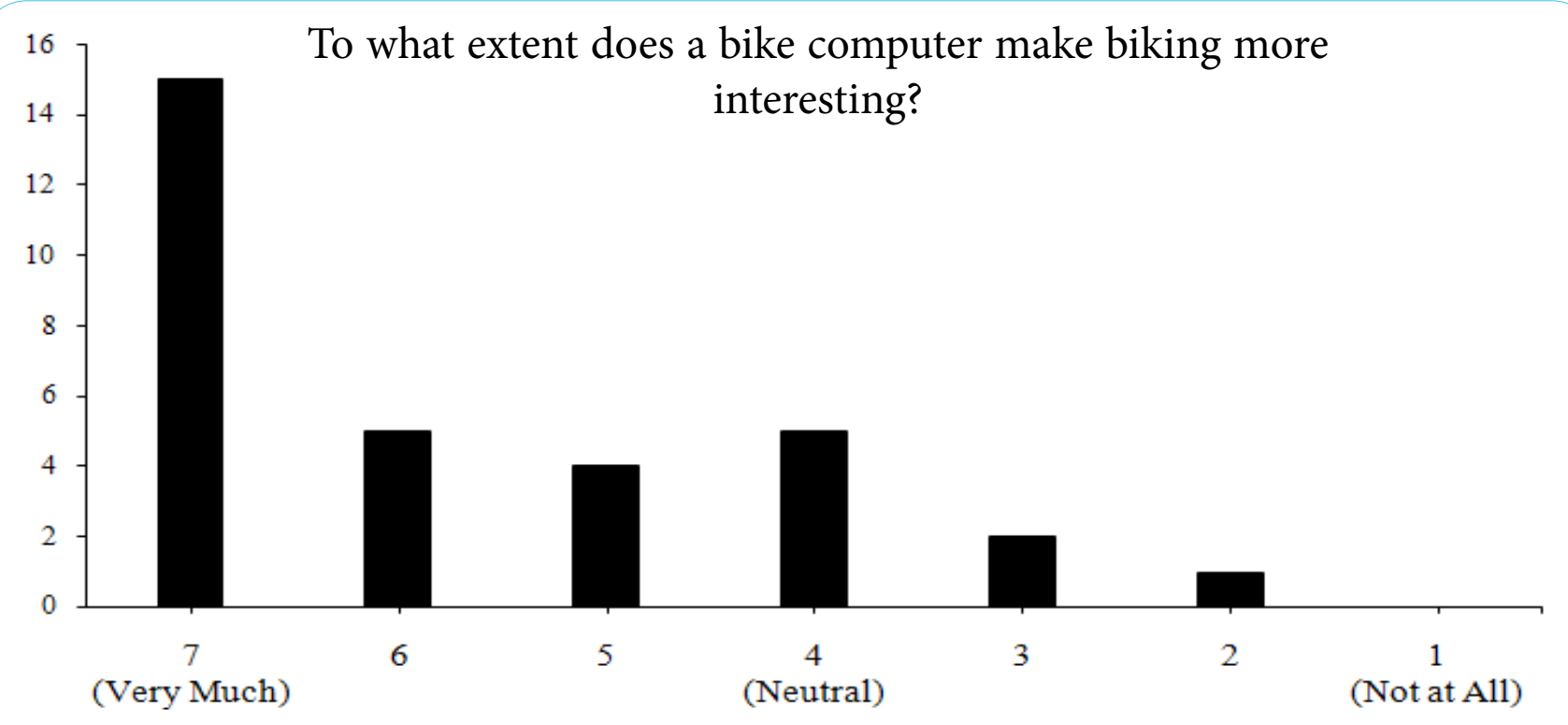

Figure 3: Reported effects of personal quantification using a bike computer on interest for avid bikers.

not find cycling a waste of time. Further they reported they found biking very fun and that biking makes them very happy. Almost without exception, bikers reported the use of personal quantification with bike computers. Bikers reported measuring over 5 variables and that they kept track of about 4 measures over the course of a year. They also reported that measuring biking behavior with personal quantification made biking even more enjoyable and interesting. These findings reflecting lifetimes of activity, interest, and personal quantification, refute claims that personal quantification unilaterally undermines intrinsic interest, enjoyment, or happiness. Indeed, these results suggest personal quantification can facilitate, rather than undermine, continued engagement in an activity. Although data is more limited, sharing quantified information via Strava with other interested individuals may make such activities even more interestingand enjoyable for some, albeit to a lesser extent than was reported for the use of biking computers in the current study.

While personal quantification with the use of a bike computer made biking more interesting and more enjoyable, these ratings were not as high as how interesting and enjoyable biking was for the participants in the first portion of the survey when respondents were asked about enjoyment in cycling in general. This may be because interest and enjoyment ratings were already reported to be near asymptotic levels. With the use of a Likert-type scale, there was little way of indicating how quantification could make biking much more interesting or enjoyable than it already was reported for the participants. Bike computers were reported to increase reported enjoyment and interest for majority of respondents. Far from being detrimental, data from this survey indicates that personal quantification may have supplemental effects on interest.

\section{Analysis of and comparison to Etkin}

As mentioned, results of the current study is not consistent with the notion that personal quantification unilaterally undermines intrinsic interest and the findings of Etkin [3]. In the study completed by Etkin [3], 105 college students were paid to spend 10 minutes coloring simple shapes (Experiment 1), 195 students were paid to wear a pedometer for a day (Experiments 2 and 3), 310 college students were paid to read for eight minutes (Experiment 4), 240 adults recruited online from Amazon's Turk were paid to read for 10 minutes (Experiment 5), and 66 students to were paid to read for 10 minutes (Experiment 6). In each experiment, either the activity that participants were paid for was overtly measured (experimental groups) or not (control groups). Then, participants ratings of interest, enjoyment, etc., were taken and in some cases the opportunity to continue in the activity from the experiment was given. In all experiments, on average the group overtly measured engaged in the measured activity, while being overtly measured, slightly more than the control group. But on average the group overtly measured reported enjoying, being interested in the activity slightly less than the control group and if given the opportunity, continued in the activity on average slightly less (e.g., stopped reading sooner) than the control group.

Bikers in the current study reported decades of engagement with exercise pursuits and cycling. The bikers in the current study were responsible for paying their own money to purchase bikes, biking computers, biking equipment, and in several cases finance international trips. Reliable bike shop bikes range in price from a few hundred dollars/euros to thousands. Tires, chains, cables and other parts wear out and must be replaced on a regular basis. Time trial bikes used by triathletes are among the most expensive bikes available. Entry fees to triathlons can be hundreds of dollars just to participate. Conversely, in Etkin's study, participants were paid to even participate in the first place. Regardless of experiment or measurement condition, all but one of Etkin's measurements of enjoyment, fun, interest, etc., hovered around 4 (neutral) and 5 (barely interesting). In contrast, bikers surveyed in the current study reported higher ratings of enjoyment, fun, and interest than in Etkin's study.

Further, the activities in the current study that were those that participants found interesting as evidenced by decades of reported engagement, as opposed to tedious experimental tasks. Bikers in the current study reported spending hundreds of hours each year biking. Conversely, most college students probably do not spend hundreds of hours of their free time coloring shapes. The use of nondescript reading of experimenter selected material is not interesting. In Etkin's studies [3], what specifically was read was not reported. For the avid reader, it is the subject of the reading that makes reading interesting to 
an individual. A mechanical engineering textbook may be interesting to some while an erotic novel is interesting to others. These interests are likely based on an idiosyncratic individual history of reinforcement for engagement in these interests. To argue that measuring reading random materials for 10 minutes will make people like reading in general less and read less as an enduring problem (regardless of topic) seems counterintuitive to addressing the subject of what people find interesting in their day-to-day lives.

It is questionable at best to extrapolate results from the brief samples of time (10 minutes) used by Etkin and others who argue external factors reduce later task engagement accurately and generalize these findings across a lifetime where individuals are freer chose what they engage with. Thus, the current study investigated what people actually do during their lifetime and found that bikers, virtually without exception, do indeed measure what they are interested in and report that measurement supplements their interest.

Etkin did, however, have over 900 participants and reported statistically significant detrimental effects of personal quantification. The small participant sample size and use of surveys in the current study is a limitation of the current study. The current study only had 34 participants and used only descriptive statistics (averages) based on results of a survey. However, the total amount of time across the lifespan regarding the activities of interest (exercise and biking) in the current report is far greater than the amount of time involved in the activities captured by Etkin's experiments. The current study assessed interests of those who bike multiple hours, multiple times per week for years versus coloring shapes for 8 minutes, reading for 10 minutes, or recording their amount walked for a single day. In sum, the total behavioral sample reported by the bikers represents a much larger sample of behavior than the very brief samples of behavior of multiple people taken by Ektin.

As the current study used a survey, it was not behavioral as defined by Bear, Wolf, and Risley [1]. The current study did not take objective measurements of behavior (biking) but took reports of behavior and behavior's measurement and reports of the behavior's relation, and measured self-reported psychological variables such as interest, enjoyment, fun, and happiness. While it may be possible to objectively define and quantify behavior related to these psychological variables such as "behavioral indicators of happiness" [12], the ultimate scientific status (and indeed existence of) these psychological variables, or hypothetical constructs, is questionable.

\section{Intrinsic and extrinsic motivation: A false dichotomy?}

Psychologists define intrinsically interesting activities as activities people do "for their own sake" and that "intrinsically motivated activities are pursued simply because they are enjoyable [3, p. 968, $13,14]$. This definition and subsequent distinction is not at all simple. A starting point might be to ask, "what makes an activity "enjoyable?" A variety of stimulus conditions and experiences could be primary and/or conditioned reinforcement for biking. For instance, is it the proprioceptive, kinesthetic, and vestibular sensations a cyclist experiences while speeding down a narrow switch-back laden mountain descent or subsequent bodily sensations after exercising? Or is it the sights and sounds during biking? Is it watching the scenery drift by as one lightly pedals through a forest while laughing with one's biking friends? Or perhaps it is pedaling up a town's steepest road at one's fastest pace, highest heart rate, highest power output and being designated as king of the mountain (KOM) by Strava as the fastest cyclist ever recorded to ride up that segment of road? One may be motivated to bike, interested in biking, for all of these reasons, for none, or for some combination of the above. Measuring, quantifying biking does not take away from or "undermine," any of the sights, sounds, proprioceptive, kinesthetic, and vestibular sensations a cyclist experiences during riding.

Especially when coupled with goal setting, quantification of an activity may set the conditions where other intrinsically interesting aspects of the activity are experienced. For example, to meet one's monthly biking distance goal a cyclist may go for a ride and during the ride the cyclist will experience all of the sights, sounds, proprioceptive, kinesthetic, and vestibular sensations mentioned above. Without measuring distance biked and a distance goal and one's relation to it, going on a ride to meet that goal would not have occurred. In this case, the contrived, "extrinsic," quantified behavior set the condition for the natural, "intrinsic reward" to be experienced. When does the extrinsic become the intrinsic or intrinsic become extrinsic? What is extrinsic? What is external to the activity, contrived, artificial? When 'extrinsic' factors are added they become part of the whole of the cycling experience.

Personal quantification and measurement are like science generally in that they add to interest and activity; they don't subtract. In an interesting parallel to the issue at hand, the Noble prize-winning physicist Richard Feynman once described an instance in which an artist once claimed that he, as a scientist, could not see the beauty of a flower. The artist claimed that science made the flower become "a dull thing." Feynman countered that the beauty available to the artist was available to the scientist as well, and that science allowed him to see more, and have more wonder than was available to the artist. "All kinds of interesting questions which the science knowledge only adds to the excitement, the mystery and the awe... It only adds. I don't understand how it subtracts" [15]. Likewise, the "natural" or "intrinsic" interest, fun, and enjoyment of an activity that is available to those who don't evaluate (or only subjectively and non-systematically evaluate their activity), is also available to those who use personal quantification to objectively and systematically measure, display and record their activity. Personal quantification adds to the excitement and awe of the quantified behavior, it does not subtract nor is it "detrimental."

\section{Play/Work false dichotomy}

Just as extrinsic and intrinsic are not mutually exclusive, play and work are not mutually exclusive and neither is exclusively good or bad, desired or aversive. Other than a derogatory insult, what is "turns play into work" supposed to mean? The English philosopher/educator L. P. Jacks observed the following:

"A master in the art of living draws no sharp distinction between his work and his play; his labor and his leisure; his mind and his body; his education and his recreation. He hardly knows which is which. He simply pursues his vision of excellence through whatever he is doing, and leaves others to determine whether he is working or playing. To himself, he always appears to be doing both."[16, p. 1-2].

jacks later asks, and answers, the question at hand:

"But what is work, and what is play? When you listen to a master performing.., or watch a Pavlova (ballerina) visibly enacting the music of the human body, arts acquired by years of the sternest discipline, is it work or play that you are witnessing? It is both.... Art and industry 
have become one. The highest kind of work and the highest kind of play are indistinguishable one from the other. They are two names for the same thing" [16, p. 30 , first emphasis added, second and third emphasis in original].

This observation holds true in modern culture. A performer or athlete having an outstanding performance is said to be "working it." Movie director Spike Lee's documentary of basketball hall of fame player Kobe Bryant is titled "Doing Work," in which Bryant repeatedly refers to his "work" as "fun" [17]. Thomas A. Edison used to say that his work was his recreation" Jacks later notes, "on the highest levels of life the distinction between labour and leisure, or between work and play fades out" [16, p. 98-99].

On ball fields across the world millions of children play baseball and softball, millions more play other sports such as basketball. Millions of all these millions of children engage in personal quantification. Baseball and softball players keep track of their "runs batted in" (RBI), batting average, errors, and more. Basketball players know how many points they score, how many fouls they have committed, how many rebounds they got. All of these statistics, all these performance indicators are measures of behavior. These measures are the players' personal quantifiers, metrics of performance. Millions know their performance numbers well into adult and even senior leagues. Millions of joggers and runners keep track of their miles run, personal records (PRs) and more. How many children learn basic math by tracking their personal quantification on the playing fields and playing courts across the globe? Far from globally detrimental, personal quantification can add to enjoyment of such activities.

In "Fantasy Sports" (also known as rotisserie or roto sports) fantasy sports players select real players for their team from a pool of all players in a sport based on the player's quantified statistics. Fantasy sports players win in fantasy sports when their roster of players have the best performance metrics over a given time period. For instance, a fantasy baseball team would accrue points for every homerun a player on the fantasy roster had in a week. Fantasy sports exist for a variety of professional sports. In sum, fantasy sports are games based largely on quantification of performance. If spending money or time is any indication, it is clear that fantasy sports players find this game based on quantification of other's performance quite enjoyable. In 2016, it was reported that over 57 million people played fantasy sports in the U.S. and Canada, which is equivalent to $16 \%$ of the population [18]. In 2015, it was reported that two popular sites in the U.S. (DraftKings and FanDuel) collected a combined 3 billion dollars in entry fees [19].

\section{Expert performance and flow}

An elite performance facilitated by behavioral quantification may result in the psychological experience of flow. Flow is characterized as a desirable psychological state involving complete involvement in an activity where time seems to fall away, action and awareness merge, one perceives personal control and agency over the activity, and the activity is perceived as rewarding [20]. Flow happens when a high skill level occurs with a high challenge level, and for this convergence of skill and challenge it is argued that there must be a clear set of goals with progress and there must be clear and immediate feedback so adjustments in performance can be a marked to balance challenges with skill [21].

Personal, behavioral quantification can provide the immediate feedback needed for clear goals and to monitor progress. Therefore, although not assessed in the current study, in addition to the many other benefits of personal quantification, facilitating expert performance and flow are likely two additional benefits of personal quantification. Achieving elite, world class, expert skilled performance in a domain (athletics, music, math) requires deliberate practice. Deliberate practice is effortful, repetitive, highly structured, goal focused, skilled activity with immediate detailed feedback maintained over extensive time periods (citations). To put it one way, "the differences between expert performers and normal adults reflect a life-long period of deliberate effort to improve performance in a specific domain....experts carefully schedule deliberate practice and limit and its duration to avoid exhaustion and burnout" [22, p. 400]. Far from detrimental to expert performance, detailed feedback, including that which comes from personal quantification of behavior, can facilitate deliberate practice which is prerequisite for expert performance. Superior expert performance occurs "in response to informative feedback during practice activities [23, p. 273, emphasis added].

The current study aimed to assess what is "intrinsically interesting" in a different manner when compared to the studies that commonly indicate that personal quantification reduces intrinsic interest and enjoyment. Rather than tedious experimenter selected tasks, the current study surveyed a group of individuals who spent a large majority of their lives engaged in exercise including cycling for decades. These individuals reported that personal quantification in their current activity, cycling, was at worst supplementary to enjoyment and interest as opposed to detrimental to it. Future research should continue to examine the relationship between personal quantification and activities that are pursued across significant periods of life rather than sample tasks used in traditional investigations on the subject. This would subsequently help determine the effects of personal quantification in ecologically valid scenarios and contribute to understanding ways to promote motivation and enjoyment in people's in day to day lives.

\section{Competing Interests}

The authors declare that they have no competing interests.

\section{References}

1. Baer DM, Wolf MM, Risley TR (1968) Some current dimensions of applied behavior analysis. J Appl Behav Anal 1: 91-97.

2. Petrow S (2016) Why that Fitbit might not be so good for you. USA TODAY

3. Etkin J (2016) The hidden cost of personal quantification. J Consum Research 42: 967-984.

4. Flora SR (1990) Undermining intrinsic interest from the standpoint of a behaviorist. The Psychol Rec 40: 323-346.

5. Flora SR (2004) The Power of Reinforcement. Albany: Sate University of New York Press, USA

6. Deci EL, Koestner R, Ryan RM (1999) A meta-analytic review of experiments examining the effects of extrinsic rewards on intrinsic motivation. Psychol Bull 125: 627-668.

7. Cameron J, Banko KM, Pierce WD (2001) Pervasive negative effects of rewards on intrinsic motivation: The myth continues. Behav Anal 24: 1-44.

8. Goetz EM, Baer DM (1973) Social control of form diversity and the emergence of new forms in children's block building. J Appl Behav Anal 6: 209-217.

9. Eisenberger $R$, Rhoades $L$ (2001) Incremental effects of reward on creativity. J Pers Soc Psychol 81: 728-741.

10. Eisenberger $R$, Aselage J (2009) Incremental effects of reward on experienced performance pressure: positive outcomes for intrinsic interest and creativity. J Organiz Behav 30: 95-117.

11. Polenick CA, Flora SR (2012) Effects of social reinforcement contingent on conventional or unconventional responses on generalized creativity by older adults in residential care. Psychol Rec 62: 631-644.

Int J Psychol Behav Anal

ISSN: 2456-3501

IJPBA, an open access journal

Volume 7. 2021. 174 
Citation: Flora S, Brown K (2021) Hidden in Plain Sight: The Psychological Benefits of Personal Quantification. Int J Psychol Behav Anal 7: 174. doi: https://doi. org/10.15344/2455-3867/2021/174

Page 7 of 7

12. Mulaire-Cloutier C, Vause T, Martin, GL, Yu D (2000) Choice, task preference, task performance, and happiness indicators with persons with severe developmental disabilities. Inter J of Pract Appro to Dis 24: 7-12.

13. Ryan RM, Deci EL (2000) Intrinsic and extrinsic motivations: Classic definitions and new directions. Contem Edu Psychol 25: 54-67.

14. Kruglanski AW, Friedman I, Zeevi G (1971) The effects of extrinsic incentive on some qualitative aspects of task performance. Jof Personal 39: 606-617.

15. Free Science Lectures (2007) Richard Feynman: The beauty of the flower YouTube.

16. Jacks LP (1932) Education through Recreation. New York: Harper \& Brothers, USA

17. Lee S (2009) Kobe: Doing Work. Bristol, CT: ESPN Home Entertainment.

18. Nower L, Caler KR, Pickering D, Blaszczynski A (2018) Daily fantasy sports players: Gambling, addiction, and mental health problems. J Gambl Stud 34: 727-737.

19. Van Natta DJ (2016) The inside story of the quick rise and quicker fall of DraftKings and FanDuel.

20. Nakamura J, Csikszentmihályi M (2001) Flow Theory and Research. In: CR Snyder, E Wright, \& SJ Lopez. (Eds) Handbook of Positive Psychology. Oxford University Press, USA.

21. Csikszentmihályi M, Abuhamdeh S, Nakamura J (2005) Flow. In: ElliotA (Ed) Handbook of Competence and Motivation. The Guilford Press, USA.

22. Ericsson KA, Krampe RT, Tesch-Römer C (1993) The role of deliberate practice in the acquisition of expert performance. Psychol Rev 100: 363-406.

23. Ericsson KA, Lehmann AC (1996) Expert and exceptional performance: evidence of maximal adaptation to task constraints. Annu Rev Psychol 47: 273-305. 